\title{
Transfer of adapted water supply technologies through a demonstration and teaching facility
}

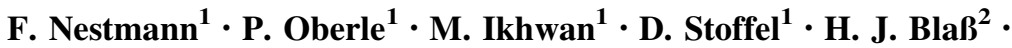 \\ D. Töws ${ }^{2} \cdot$ S. Schmidt ${ }^{3}$
}

Received: 26 February 2016/Accepted: 11 May 2016/Published online: 26 May 2016

(c) The Author(s) 2016. This article is published with open access at Springerlink.com

\begin{abstract}
Water scarcity can be defined as a lack of sufficient water resources or as the limited or even missing access to a safe water supply. Latter can be classified as 'economic water scarcity' which among others can commonly be met in tropical and subtropical karst regions of emerging and developing countries. Karst aquifers, mostly consisting of limestone and carbonate rock, show high infiltration rates which leads to a lack of above ground storage possibilities. Thus, the water will drain rapidly into the underground and evolve vast river networks. Considering the lack of appropriate infrastructure and limited human capacities in the affected areas, these underground water resources cannot be exploited adequately. Against this, background innovative and adapted technologies are required to utilize hard-to-access water resources in a sustainable way. In this context, the German-Indonesian joint R\&D project "Integrated Water Resources Management (IWRM) Indonesia" dealt with the development of highly adaptable water technologies and management strategies. Under the aegis of the Karlsruhe Institute of Technology (KIT) and funded by the German Ministry of Education and Research (BMBF), these innovative technical concepts were exemplarily implemented to remedy
\end{abstract}

F. Nestmann

franz.nestmann@kit.edu

1 Institute for Water and River Basin Management (IWG), Karlsruhe Institute of Technology (KIT), Kaiserstrasse 12, 76131 Karlsruhe, Germany

2 Research Center for Steel, Timber and Masonry - Timber Structures and Building Constructions (VA), Karlsruhe Institute of Technology (KIT), Kaiserstrasse 12, 76131 Karlsruhe, Germany

3 KSB AG, Johann-Klein-Strasse 9, 67227 Frankenthal, Germany this deficiency in the model region Gunung Sewu, a karst area situated on the southern coast of Java Island, Indonesia. The experiences gained through the interdisciplinary joint $R \& D$ activities clearly showed that even in the case of availability of appropriate technologies, a comprising transfer of knowhow and the buildup of capabilities (Capacity Development) is inevitable to sustainably implement and disseminate new methods. In this context, an adapted water supply facility was developed by KIT which hereafter shall serve for demonstration, teaching, and research purposes. The plant's functionality, its teaching and research concept, as well as the design process, which was accomplished in collaboration with the University Gadjah Mada (UGM), Yogyakarta, Indonesia, is the content of this present paper.

Keywords Water supply · Adapted technology · Capacity development - Pump as turbine - Wood stave penstock

\section{Introduction}

According to the United Nations, some 1.2 billion people around the world, which equals more than one-sixth of the world's population, live in the areas of physical water scarcity; almost 500 million people are approaching this situation (UN Water 2007). Another 1.6 billion people face economic water shortage, since many countries suffer from a severe lack of adequate infrastructure as well as limited human capacity to sustainably utilize existing and sometimes hard-to-access water resources.

Physical water scarcity is a common problem in karst regions, which cover more than $10 \%$ of the world's icefree land surface (Ford and Williams 2007). Due to the karstified underground with high infiltration rates and 
lacking storage possibilities on the surface, karst areas are very often characterized by severe water shortages. At the same time, mostly there are large underground water resources which could be used for an improvement of the local water supply situation. However, difficulties arise during exploration and exploitation of these resources out of the heterogeneous spatial distribution and thus poor accessibility associated with high extraction costs. Here, the location deep underground as well as the vulnerability to contamination due to the low filtration rate of carbonate rock have to be mentioned as typical constraints. Especially in karst regions in less or least developed countries, these constraints additionally lead to economic water scarcity. As a consequence, innovative concepts and adapted technologies are required to sustainably exploit karst aquifers. This requirement does concern the entire water cycle, including exploration, exploitation, and distribution of water resources, as well as an associated quality assurance and wastewater treatment.

In this regard, the German-Indonesian R\&D project "Integrated Water Resources Management (IWRM) Indonesia", an association of scientific and governmental institutions as well as of companies from both countries, was working on the development of adapted technologies and management strategies (e.g., Nestmann et al. 2010, 2012). The goal was to sustainably improve the water supply of the karst area Gunung Sewu, situated in the district of Gunung Kidul on the southern coast of central Java and serving as 'reference region' for the R\&D activities. The challenges experienced, such as demanding natural boundary conditions (e.g., high temperature and humidity, extreme discharge gradients), complex sociological conditions as well as insufficient technical, and financial and human capabilities stand representatively for other developing countries and remote regions. Hence, all development work aimed for a high adaptability of the technologies and concepts, which equals a high potential for multiplication to other karst and non-karst regions suffering from similar constraints.

\section{Technology transfer approach}

In general, technology transfer can be defined as a process to transfer an innovative technology from developed regions to less developed areas. Many researchers agree that technology transfer is a concept that is broader than the acquisition of physical assets and operating skills, since it aims to increase the technological capabilities of the receptor (e.g., Madu 1989; Yin 1992; Putranto et al. 2003). These capabilities include the understanding of the need of technology, the technology's functionality, as well as the ability to autonomously manage and adapt the technology.
The measures associated with the technology transfer are carried out during the transition process and focus on all relevant hierarchical levels, from the operational personnel to the decision-makers.

In this context, UN Water (2009) reports that the introduction and dissemination of adapted and innovative technologies to less or least developed countries are a major challenge, e.g., due to the people's lacking access to new technologies and limited human capacities or unwillingness to absorb new methods and approaches. Considering these constraints, one key message from UN's technological innovation report is that "impediments to the dissemination of technology must be overcome if developing countries are to benefit from innovations developed in richer countries".

One strategy to meet the above-stated challenges is by demonstrating the functionality and applicability of highpotential technologies through the implementation of pilot plants resp. reference facilities. Hereby, the assessment of the technical viability can be conducted in cooperation with the receptors to gain their acceptability for the further usage of the technology. Khennas and Barnett (2000) defined this strategy as the first step, the so-called 'technological phase'. The subsequent steps comprise a 'social phase', where the acceptance of the stakeholders shall be gained through the utilization of the technology, as well as a 'financial phase', where the operators shall be qualified to an economically sustainable utilization through the proper management of the facility.

As stated before, the joint R\&D project "IWRM Indonesia" aimed at the development and the introduction of adapted technologies in the water sector of karst areas. To transfer the developed technologies, the focus was set on the exemplary implementation of the adapted solutions. In this context, one major achievement is the erection of a decentralized water supply plant (named after its location 'Bribin') located 100 m below ground (Oberle et al. 2016). Here, a karst river is dammed up by a barrage, creating an underground water storage which is managed by means of a hydropower-driven pumping system (Oberle et al. 2009).

Bribin has been operated continuously since 2011, whereby the water supply for some 75.000 people was improved from less than $10 \mathrm{~L}$ per capita per day (lpcd) to almost 30 lpcd (Oberle et al. 2016). Based on KIT's continuous improvement of local human resources capacities during the initial 3 years of operation (mid of 2011 to mid of 2014), the supply capacity can be further increased. Thus, the first two phases of Khennas and Barnett (2000) approach have been successfully completed, since the plant is operated under full responsibility of the local personnel in years. The third phase of the mentioned approach refers to the evaluation of an economically sustainable operation. Based on the first 3 years of continuous operation, the 
O\&M-related costs of Bribin show considerable economic and ecologic advantages compared to the attempts of the conventional water supply (e.g., electrically driven pumping system). The main reason is the substantial demand for external and costly energy carriers to operate the conventional supply systems, which is not the case in Bribin.

In the context of the current project area, the share of population supplied by Bribin shows that a single plant will not be able to cover the water needs of the entire area of Gunung Sewu. In this regard, a multiplication approach concerning the implemented underground water extraction concept is one of the major objectives for the future development of this area. Furthermore, the multiplication attempts can be broadened to other areas in Indonesia and further countries affected by similar challenges.

Due to the uniqueness of each region afflicted with difficult-to-access water resources, an applicable water supply concept has to be adaptable to the local natural and sociological boundary conditions to avoid negative impacts, e.g., on the local ecology. Since the overall concept implemented in Bribin might not be transferable to arbitrary locations (e.g., due to different hydrogeological situations, high porosity of the surrounding bedrock, etc.), a supplementary conception was developed by KIT which is more independent from the geological boundary conditions. This second concept relinquishes the installation of an underground barrage to dam the karst river for the benefit of a wood stave penstock to provide the required hydraulic head for the hydropower-driven pumping system. As a result of its energetic independence and its high constructive flexibility, this concept is predestinated for decentralized surface and underground applications.

\section{Application of a demonstration facility}

Essentially, the water supply facility Bribin was implemented for four major reasons: (1) To develop and validate an innovative and sustainable hydropower-driven water supply system, (2) to verify that water storage in a karst environment is possible depending on the local geological conditions, (3) to continuously supply the people of $G u$ nung Sewu with water, and (4) to serve as demonstration object for researchers and officials in charge to develop resp. improve the water supply in their home region. However, the remote location of the plant constrains the broader dissemination of the technologies applied. Therefore, to intensify the associated multiplication processes, the second-developed water supply concept was implemented as a demonstration, teaching, and research facility in close proximity to the city of Yogyakarta, Java, and Indonesia (Fig. 1). The city of Yogyakarta, as the capital of Yogyakarta Special Province (DIY), is home of various internationally accredited universities, non-governmental organizations, regional public authorities, and industries. Therefore, the staff members and students (various fields of studies are approached, e.g., mechanical and civil engineering) of these institutions are the target groups regarding the aimed technology and knowhow transfer.

Out of a widespread search for locations within the city surrounding area, it was decided to implement the facility on the campus of the University Gadjah Mada (UGM), situated close to the center of Yogyakarta. The chosen site on UGM campus is characterized by an existing surface drainage system which also drains the residual irrigation water from close-by agricultural areas. Here, a geodetic height difference of approx. 11 meters associated with a discharge range of 25 (dry seasons) to 60 (rain seasons) liters per second was identified. Based on these preconditions, the theoretical hydropower potential of this site totals to approx. 2.6-6.3 $\mathrm{kW}$. An inevitable precondition which had to be respected during design phase was the preservation of the channel's initial purpose, both during operation and downtimes of the demonstration facility. In total, three main objectives are met at this site, namely to serve as teaching facility, field laboratory for scientists and students, and as demonstration object for various stakeholders. Thus, the technology and knowhow transfer process will benefit from this central location.

\section{Functionality and applied technologies}

The main idea regarding the plant's function is to demonstrate a concept to partially convey water of a stream to a higher level using the available hydropower potential. To introduce this idea, the implemented hydropower-driven water supply system conveys the water to an elevated tower (located close to the plant's inlet area, Fig. 2). After passing the tower's peak, the supply discharge is fed back by gravity into the inlet pool, which leads to the following advantages: the water conveyance to a higher energetic level using the local hydropower potential is visualized and the additional discharge through the loop system can assure the facility's all-time operability also during times of extreme low discharge (e.g., peak dry season). On the plant's downstream side, the water used for power generation is discharged into a tailwater pool and back into the existing channel system, respectively.

In general, the plant design contains five major components as shown in Fig. 2: (1) The inlet basin as branch of the channel system where the hydraulic head can be varied in a range of $10.5 \pm 0.5 \mathrm{~m}$, (2) the wood stave penstock which connects the inlet basin and (3) the powerhouse, including the adjoining tailwater pool, (4) the 'testing area' as part of the supply pipe (here different flow resistances can be simulated), as well as (5) the elevated tower where the water is transferred to. The two outstanding 


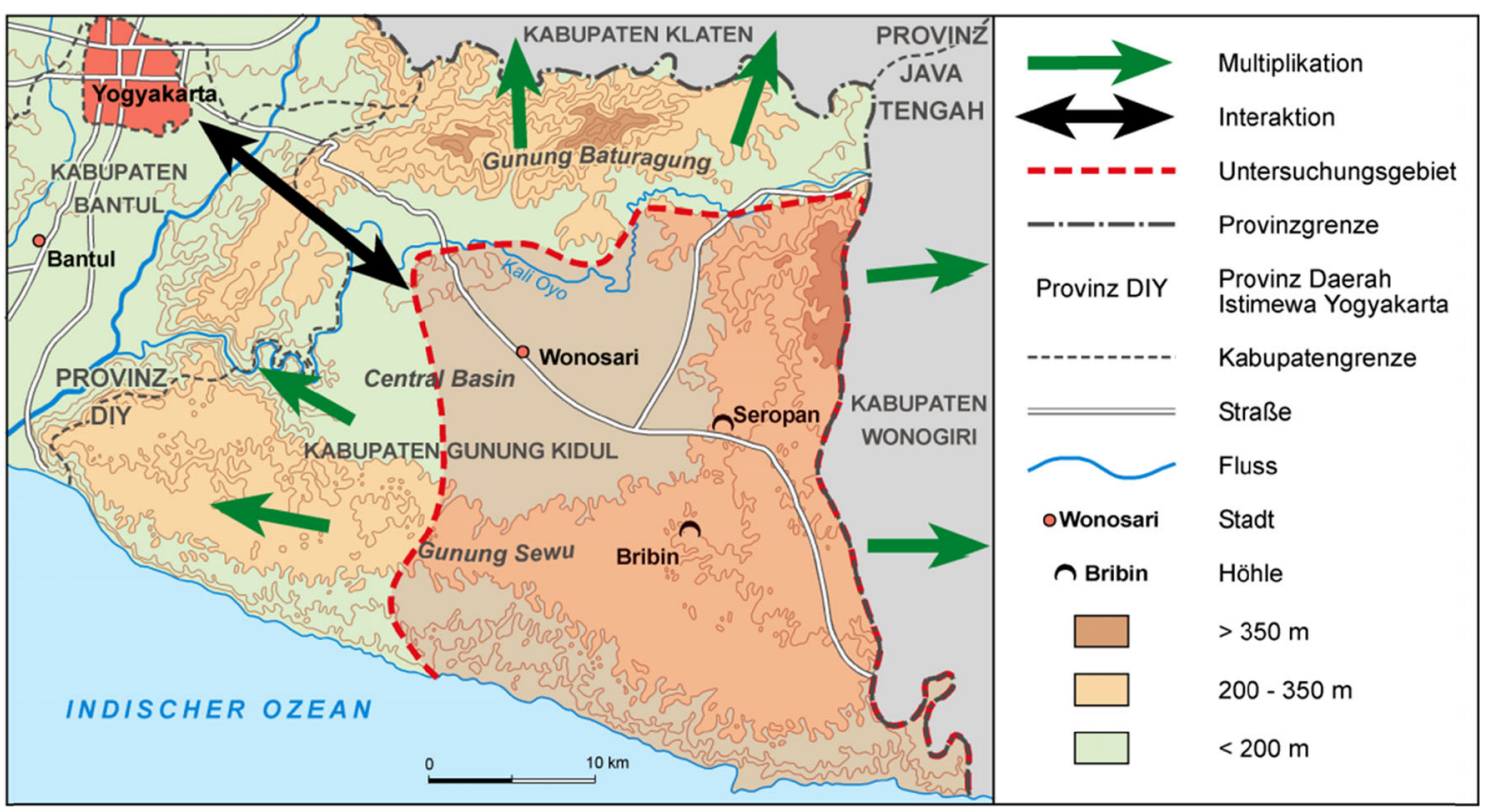

Fig. 1 Project area Gunung Sewu and city of Yogyakarta as the capital city of Yogyakarta Special Province (DIY)

Fig. 2 3D CAD model of the water supply facility developed by KIT (Banfi 2012)

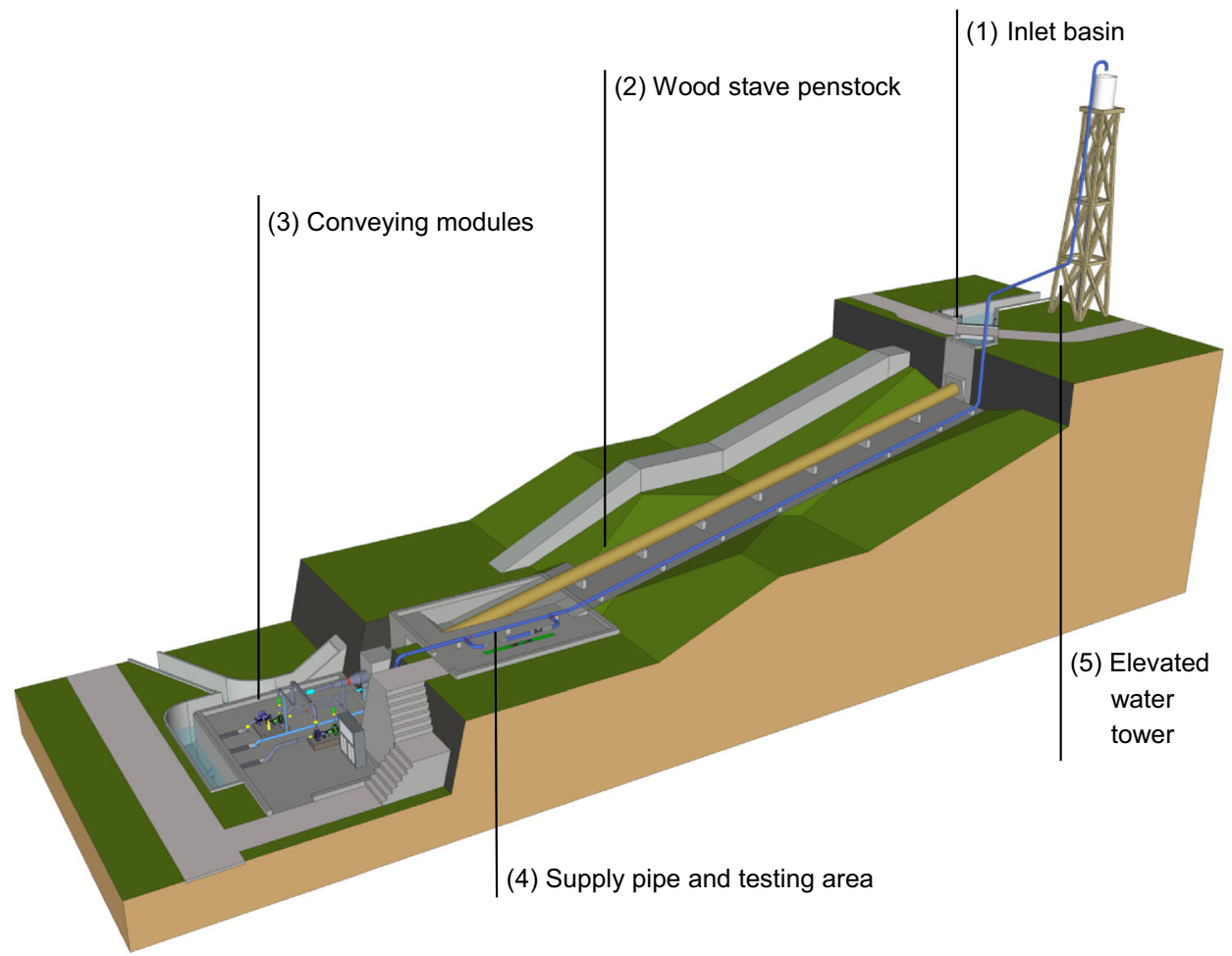

technological features are the wood stave penstock and the hydropowered supply system consisting of several socalled water conveying modules as unit of a reverse-driven centrifugal pump ("Pump as Turbine", PAT) driving a high-pressure feed pump (Fig. 3). Both techniques are highly applicable under various boundary conditions and are thus predestinated for decentralized application in remote and difficult-to-access regions with poor infrastructure. Further discussions regarding the wood stave penstock and the PAT-based water supply system will be presented in Sects. "Wood stave penstock" and "Hydropower-driven water supply", respectively. 
Fig. 3 Wood stave penstock (left) feeding the PAT-driven water supply system (right) of the demonstration facility
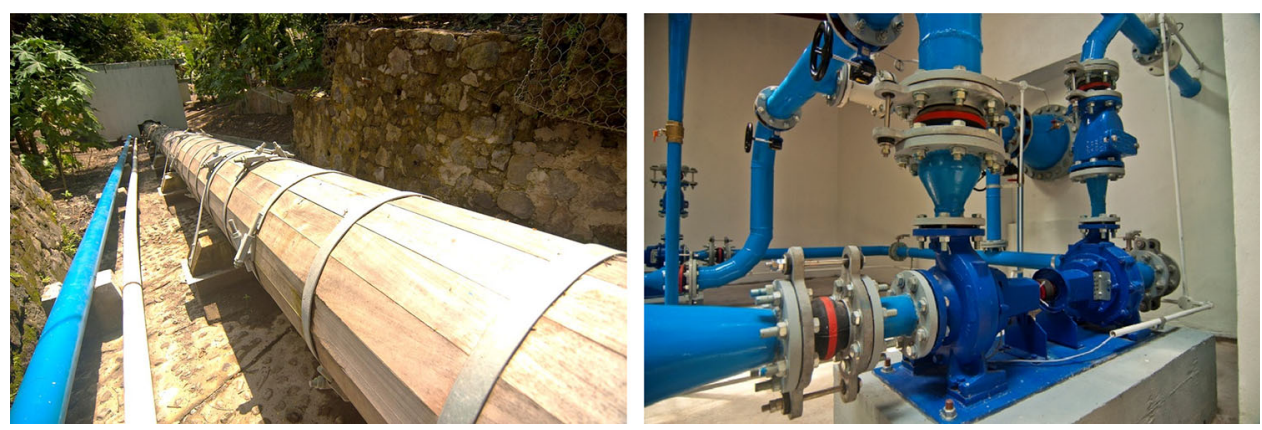

\section{Benefit as teaching and research facility}

The main focus of the desired technology and knowhow transfer is the establishment of a deep understanding to the target persons regarding functionality, proper utilization, and added value of the applied technologies. Concerning this, an interactive teaching concept was elaborated, which comprises the controllability resp. variability of operating parameters, such as hydraulic head, number of simultaneously operated modules, and pumping head. Accordingly, the learner can perceive the interconnection of the plant's characteristic values through gaining own practical experiences.

Furthermore, potential research topics that can be pursued by local scientists refer, among others, to the longterm performance of a surficial applied wood stave penstock (e.g., regarding aging of the timber, fungal, or insect infestation) as well as of the PAT-driven water supply system (e.g., regarding alteration of the machine's characteristics). Suchlike research topics are of great interest for various fields of studies (e.g., timber, mechanical, civil, and hydraulic engineering), whereby a widespread dissemination of the associated knowledge can be achieved.

\section{Wood stave penstock}

According to Blass and Fellmoser (2005) and Fellmoser (2007), wood stave pipelines were mainly used in the nineteenth century in North America as inlet pipes for hydroelectric power stations. After a decrease mid of the twentieth century, the application got new impulses in recent years due to the intensified utilization of regenerative resources and the desired regional development of rural areas in emerging or developing countries. Some of the main advantages applying wood stave pipelines are:

- Flexible construction Unlike steel and concrete pipelines, wood stave pipelines are not delivered in large segments, but in small discrete parts. Thus, an on-site assembly is possible without the need of complex equipment. Therefore, wood stave pipelines can easily be applied in remote or difficult-to-access environments (e.g., mountainous region, karst caves). In general, this kind of pipeline can be produced with diameters from 0.5 to $4 \mathrm{~m}$ and for pressures up to six bars. Due to timber's low sensitivity to temperature variations, pipe lengths of several kilometers are feasible without any flexible joints to compensate temperature-induced expansions.

- Low costs The manual on-site construction is especially advantageous in emerging and developing countries due to the common limitation of available equipment. In addition, here, the usually minor labor costs lead to comparatively low asset costs.

- Advantageous operation Wooden pipelines do not suffer from increased roughness when aging. Instead, forming of a biofilm smoothens the pipeline's inner surface, thereby, lowering its hydraulic coefficient.

- Environmental compatibility Utilizing timber produced locally in plantations (which are characterized by sustainable forest management) can contribute to environmental protection. Here, the required energetic input is distinctly lower than for the generally energyintensive steel production.

- Durability Timber penstocks can show a high durability as long as the material is permanently saturated and consequently protected from direct insolation.

Regarding the construction of wood stave penstocks, Blass and Fellmoser (2005) and Fellmoser (2007) had carried out preliminary studies within the framework of the BMBF joint-project which had concentrated on three main topics, namely: (1) The influence of moisture content on basic properties of different timber species, (2) the force transmission from the wood stave pipeline to circumferential spanned steel clamping rings (see Sect. "Construction guidelines and application of steel clamping rings"), as well as (3) adapted connection techniques between wood stave pipelines and steel connectors using a concrete abutment (see Sect. "Connection techniques for wood stave penstocks and steel connectors"). 


\section{Properties of different timber species}

These studies resulted in general construction guidelines, which contain a standardized analysis of available timber specimen as initial working step. Here, the variability of the timbers' properties is evaluated as the basis for the successive selection process. Regarding the here described penstock application, the following kinds of local timber were assessed in terms of their mechanical properties: Durian (Latin: Durio spp), Bayur (Latin: Pterospermum javanicum), Surian (Latin: Toona sureni), and Teak Heartwood (Latin: Tectona grandis). These investigations were accomplished in cooperation with UGM's Laboratory of Structural Engineering (Indonesian: Laboratorium Teknik Struktur). To ensure the implementation's sustainability, all specimens were procured from local plantations.

Usually, surficial or near-surface applied wood stave pipelines require a pre-installation treatment with a pressure impregnation to protect the material against termites (Fellmoser 2007). However, regarding the facilities objective to supply drinking water, it was decided to relinquish this protective layer due to hygienic reasons. In addition, this also opened a new field of research in terms of investigating the timber's durability within the scope of a surficial application in a tropical environment (i.e., perennial high temperature and humidity). In this context, the specimens' resilience against termites was assessed in cooperation with the Faculty of Forestry (Indonesian: Fakultas Kahutanan) of UGM, using dry wood termites (Latin: Cyprotermes curvignatus) and subterranean termites (Latin: Macrothermes sp) with due regard to the surficial application. As a result, Teak Heartwood was chosen as the most suitable material.

\section{Construction guidelines and application of steel clamping rings}

The general working steps related to a wood stave pipeline's assembly are illustrated in Fig. 4. In principal, its functionality is based on a circumferential and longitudinal installation of single staves (Fig. 4b, c) connected by tongue and groove joints (Fig. 4d). For the assembly, every second stave is displaced in relation to the adjacent stave by half of its length (Fig. 4c).

Since the swelling process is essential for the pipe's tightness, it has to be ensured by utilizing wood staves with proper moisture content ranging from 16 to $18 \%$ (Fellmoser 2007). The swelling occurs during the pipe's filling, wherefore the assembly is circumferentially spanned with steel clamping rings to keep the pipe in shape (Fig. 4e, f). These rings are arranged in spiral pattern in terms of adapting the distance between single rings according to the hydrostatic pressure gradient inside the pipeline. Thus, a uniform stress distribution can be achieved.

Figure $4 \mathrm{f}$ shows the cross section of the filled pipe after accomplishing the swelling process. To continuously ensure the pressure-dependent tightness, the pipe's permanent filling is essential, since an alternated dehydration and filling could induce deformations and cracks as well as the pipe's exposure to fungal and insect infestation.

The adjustability of wooden pipelines to the local terrain is considered as advantageous; however, there are some limitations that need to be considered. First, the feasibility of a bending depends on a minimum radius of curvature of 30 times the pipeline's diameter. Second, wooden fittings, e.g., tee branches or reducers, are not feasible contrary to fittings made of steel, concrete, or polymer material. Nevertheless, through specific integration of steel fittings, close changes in direction, branching, joining, etc., can be implemented. Against this background, the connectivity of the wooden section with parts of different materials is of great interest.

According to the mentioned construction guidelines as well as to the on-site boundary conditions (water yield, hydraulic head) stated in the previous chapter, the penstock dimensions resulted to $30 \mathrm{~m}$ in length and $0.5 \mathrm{~m}$ in diameter. Latter refers to the stated minimum design diameter for wood stave pipelines (see Sect. "Wood stave penstock").

\section{Connection techniques for wood stave penstocks and steel connectors}

Optimized solutions to connect a wood stave penstock with a steel connector inside a concrete abutment had been developed by KIT through experimental studies (Fellmoser 2007). Here, the water tightness is achieved by two subsystems which have to be implemented in parallel (Fig. 6).

One sub-system prevents a leakage at the contact surface between wood staves and concrete abutment. Here, leakages are expected during the pipe's initial filling, since the timber's swelling process needs time to seal this area. Note that this sealing procedure also applies for initial leakages at the contact surfaces between single staves (Fig. 5, left), which will also vanish until the swelling process has ended. The second sub-system prohibits a water flow between steel connector and concrete abutment through the installation of swelling tapes. These tapes' size will also increase when coming into contact with water, whereby the desired tightness will be achieved until the end of the swelling process. Figures 6 and 7 illustrate the application of both techniques referring to the example of the here discussed demonstration water supply facility.

As experienced during the implementation at UGM, also after the completion of the swelling process, leakages 


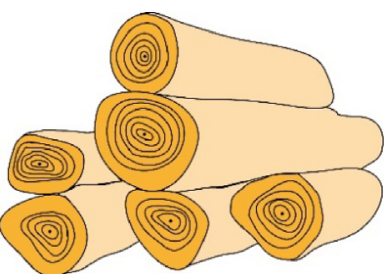

(a) Wood logs from plantations with sustainable forestry

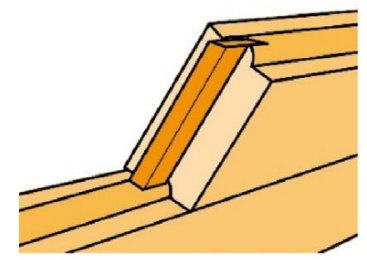

(d) Tongue and groove joint in circumferential and longitudinal direction

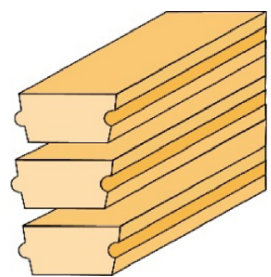

(b) Kiln dried, sawed and milled wood staves

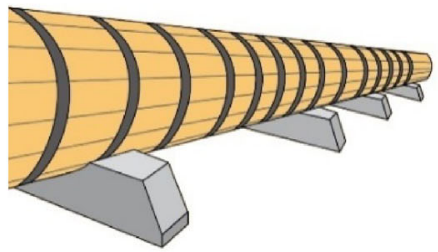

(e) Completed wood stave pipeline with steel rings, supported by concrete saddles

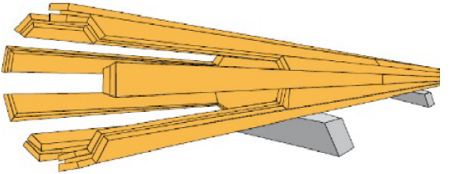

(c) Assembly of the wood stave pipeline; every second stave is displaced to the neighbored stave by half of its length

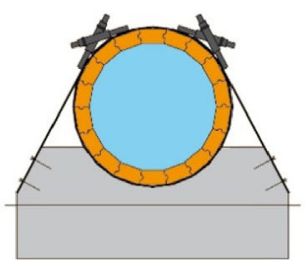

(f) Cross-section of wood stave pipeline filled with water

Fig. 4 Illustration of the working steps for the construction of a wood stave pipeline

Fig. 5 Expected leakages during initial filling (left) will vanish when reaching the desired tightness at the swelling process's end, Capacity Development by KIT regarding the required pre-stress of the steel clamping rings (right)
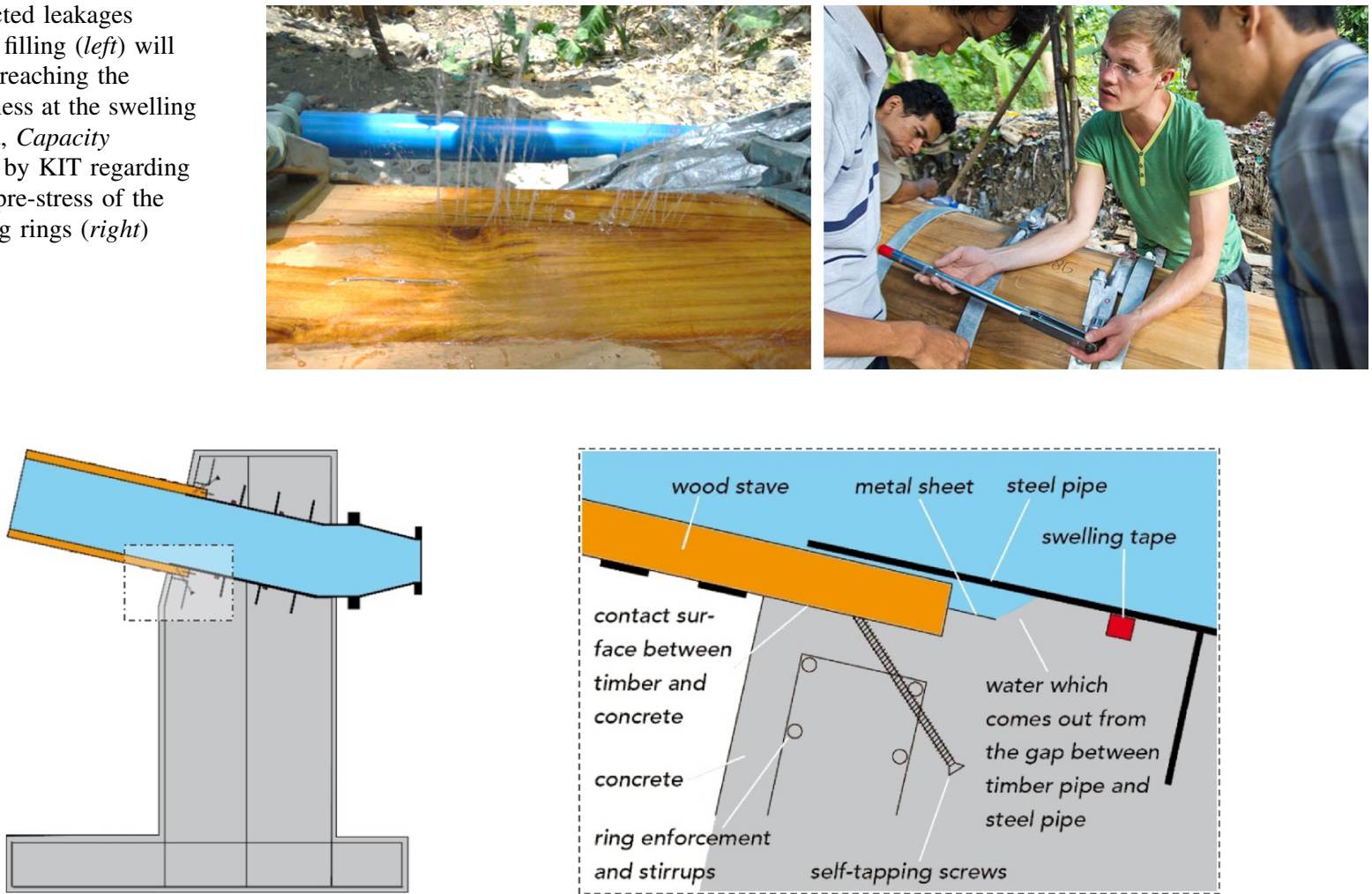

Fig. 6 Exemplary illustration of a construction to ensure the tightness between wood staves and steel connector

might occur at the abutment due to usage of poor materials and/or a deficient concreting process. Especially implementations in emerging or developing countries might be afflicted with these constraints, since the working conditions are commonly limited for technical and knowhow-related reasons.

In case of the implementation at UGM, an insufficient consolidation of the concrete lead to a remaining leakage at 

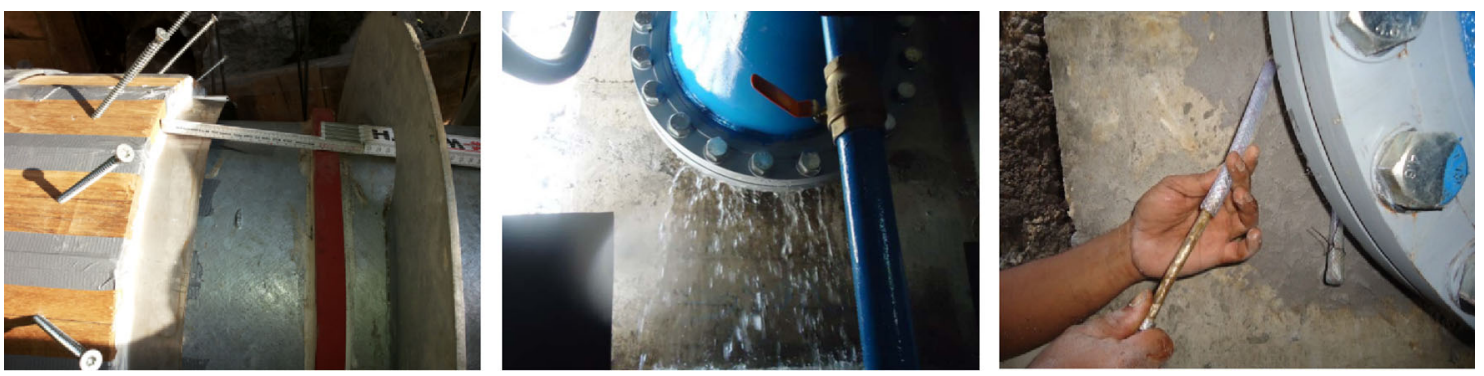

Fig. 7 Preparations of the connection between penstock and steel connector (left), leakage due to deficient concreting process (mid), injection to seal the contact surface between concrete and steel connector (right)

the contact surface between concrete and steel connector. This failure is usually related to poor equipment and/or insufficient accuracy regarding the construction process. Commonly, this problem is resolved through an injection campaign (Fig. 7) which is an adequate standard procedure applicable through local personnel. Hereby, epoxy resin is pressed into the concrete abutment through boreholes, which had been drilled on the connector's circumference. To get the optimum result, the correct orientation of the boreholes needs to be assured to meet the problematic area as close as possible. Applying this procedure, the desired tightness was achieved. Based on this experience, the preparation of such injections as potential after-treatment is reasonable. Here, the required rubber hoses can be installed prior to the concreting process; therefore, the contact area between concrete and steel connector can be met directly. If the desired tightness is achieved immediately, experience proofed that the hoses shall remain opened with regard to a potential later utilization.

\section{Hydropower-driven water supply}

The water supply system is attached to the wooden penstock as shown in Fig. 2. Here, a highly adaptable supply concept was developed by KIT which excels both through high robustness and high efficiency. This supply system is based on so-called 'water conveying modules', which contain a reverse-driven pump (so-called 'Pump as Turbine', PAT) driving a directly coupled high-pressure feed pump. In general, hydropower potentials are utilized applying hydraulic turbines, which can be adjusted during operation in accordance to the respective discharge conditions. However, due to this adjustability, these machines are high-tech applications with a complex structure, leading to high investment and maintenance-related costs.

As opposed to this, the 'Pump as Turbine' (PAT) technology is an alternative approach to utilize hydropower potentials with less technical and economical effort. By reversing a centrifugal pump's operation, a torsional moment is induced at the machine's shaft which can be used to drive any kind of working machine (e.g., generator, feed pump); however, mostly electricity is generated. In general, PAT applications can usually be found for pressure management and energy recovery purposes within water distribution systems (pressure reduction between elevated and low level tank, pressure control in close-loop systems), for residual water utilization and retrofitting of small hydropower systems, as well as in numerous industrial applications (e.g., pressure control in cooling systems, reduction of process water pressure). In general, reasons to use a PAT are among others:

- High availability Due to the production in large quantities, various types of centrifugal pumps as well as the related spare parts are available worldwide.

- High robustness Compared to common turbines, a PAT is characterized by low complexity and high robustness, which leads to low effort regarding the machine's operation and maintenance (O\&M).

- Low costs Referring to the large production numbers as well as to the technology's robustness, both investment and O\&M-related costs are comparatively low.

\section{Attainable efficiencies of a PAT}

Through appropriate machine selection under consideration of the respective hydraulic boundary conditions and, if required, in association with a mechanical optimization of flow-guiding components (e.g., smoothing the surface of impeller and casing, reworking of the impeller's geometry), PAT-efficiencies in the range of $80 \%$ are feasible. This range, which almost corresponds with the ones of common turbines, still depends on machine-specific characteristics such as size, number of flow channels, machine type etc. The results of comprehensive studies by KIT regarding this topic can be found, e.g., in Singh (2005).

Regarding a PAT's operational scope, the absence of any control device, which is beneficial in terms of the machine's low complexity, limits the operating (resp. 
discharge) range at high efficiency. Thus, most widely constant conditions are required to avoid partial load or overload operation as far as possible (Fig. 8). However, to manage certain discharge variability, a modular buildup can be implemented in terms of parallel operation of several machines as exemplarily shown in Fig. 8. Thus, each machine can be operated at its respective best efficiency point.

\section{Dimensioning of PAT-based water conveying modules}

Various pump manufacturers can provide characteristic curves for the turbine mode of their centrifugal pumps, which are mostly experimentally gained through test-rig runs. However, despite the PAT's high potential for application in some companies, it is still considered a niche product, whereby the machines performance curves are sometimes only available for the pump mode. To obtain valid information about the reverse mode's characteristics, the machine's pre-installation measurement on a test-rig is required. However, this approach is not always feasible, since it would distinctly offset the PAT technology's lowcost and low-effort advantages.

Against this background, various analytical methods were developed, among others by Chapallaz et al. (1992) and Gülich (2010) to predict the performance in reverse operation. Regarding available centrifugal pumps, these empiric procedures allow a pre-calculation of the hydraulic head, discharge, efficiency, etc., for the turbine mode's best efficiency point. These calculations are referring to the machine's design parameters in the pump mode's best efficiency point. Usually such correlations are valid for a particular range of the pump mode's specific speed (Eq. 3.5), wherefore the gained results for the reverse operation's parameters might be afflicted with a certain spread.

Nevertheless, this is a valid approach to get an idea about the performance of locally available centrifugal pumps in turbine mode. In addition, the uncertainties associated with this analytical approach can be compensated by a stepwise implementation of the machinery combined with an on-site validation of the relevant design parameters. Available water yield, attainable hydraulic head, and required pumping head are site-specific parameters and have, therefore, to be investigated prior to the design process of the water supply system. Based on this information, the overall goals of the dimensioning process are an all-season operability of the supply system as well as a high utilization of the commonly fluctuating water yield. Especially in areas of high discharge gradients (e.g., tropical karst regions), the fulfillment of both requirements is very demanding with due regard to a preferably low complexity of the system as well as to low investment and O\&M-related costs.

Referring to a lacking data base, the construction of the water supply facility can be accomplished in a stepwise approach. For instance, depending on the data quality, the supply system's basic configuration could comprise only a partial utilization of the chosen site's assumed water supply potential. Subsequently, the system can successively be extended based on further information gained during operation. Nevertheless, this strategy requires a constructive preparation and flexibility of the water supply system, so later extensions only cause minor technical and economical effort. Inherently, the entire design process has to
Fig. 8 Exemplary efficiency and power curves of four pumps as turbines $\left(n_{\mathrm{q}}=37.5 \mathrm{~min}^{-1}\right)$ without control devices in single and parallel operation modes, modified from Störzer (2009)

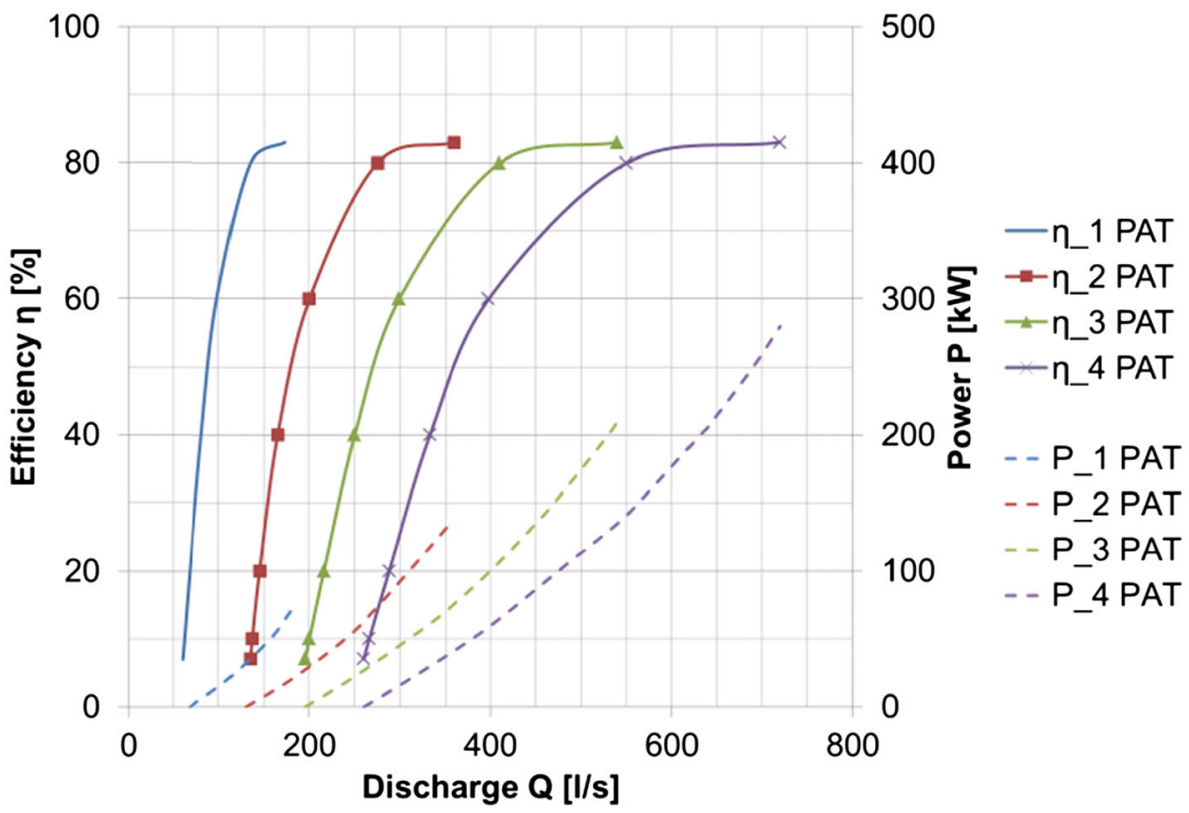

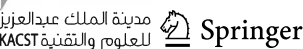


be associated with economic efficiency calculations, so especially in case of a stepwise approach, the facility's profitability is given at all times.

In general, the theoretical hydropower potential of a certain site cannot be exploited entirely, since the utilization of a PAT or common turbine is always afflicted with machine-specific energetic losses $\eta_{\mathrm{PAT}}$ (this applies for all kind of prime movers). Considering also the absorption capacity $Q$, hydraulic head $H$, density of water $\rho$, and gravity $g$, the power generated by a PAT (or turbine) can be defined according to Eq. 3.1.

$P_{\mathrm{PAT}}=\rho g Q H \eta_{\mathrm{PAT}}$

This power serves as driving force for the here discussed water conveying modules. To evaluate the power which is consumed by the feed pump ( $\left.P_{\text {pump }}\right)$ to supply water to a higher elevation; however, the efficiencies of interposed couplings and gearboxes $\left(\eta_{c, g}\right)$ between prime mover (PAT or turbine) and working machine (pump) have to be considered as shown in Eq. 3.2.

$P_{\mathrm{PAT}}=\frac{P_{\mathrm{pump}}}{\eta_{c, g}}$

Is $P_{\text {pump }}$ further on substituted in accordance to Eq. 3.3 (which contains the parameters supply discharge $q$, pumping head $h$, and pump efficiency $\eta_{\text {pump}}$ ), the total power balance of the water supply module is defined as shown in Eq. 3.4. Here, it is illustrated that the water demand of the PAT(s) distinctly prevails, since the pumping head mostly exceeds the pressure head by far. This has to be considered, since the available water yield has to be divided in the absorption capacity of the PAT(s) and the supply discharge of the feed pump(s). In this context, the minimum discharge is of vital significance for a proper dimensioning of the conveying module(s) in terms of all-season operability. In general, a profound determination of the hydrologic conditions (water yield, minimum, and maximum discharge, etc.) shall preferably be based on data time series of an adequate time span. Here, duration of at least 10 years is reasonable to ensure a statistical certainty. In the case of lacking data resp. if this amount of time cannot be spent prior to the development and implementation process, further information, such as spatial and temporal rainfall distribution, hydromorphological characteristics, etc., shall be considered in particular.

$P_{\text {pump }}=\frac{\rho g q h}{\eta_{\text {pump }}}$

$P_{\mathrm{PAT}}=\rho g Q H \eta_{\mathrm{PAT}}=\frac{\rho g q h}{\eta_{c, g} \eta_{\mathrm{pump}}}=P_{\mathrm{pump}}$
A valid approach to select suitable machines for the pump and the turbine application is to consider the specific speeds $n_{\mathrm{q}}$ which can be calculated as shown in Eq. 3.5. This value depends on the PAT's (pump's) operating speed $\mathrm{n}_{\text {PAT }}\left(n_{\text {pump }}\right)$ as well as on its absorption capacity $Q_{\text {opt }}$ (supply discharge $q_{\text {opt }}$ ), and hydraulic head $H_{\text {opt }}$ (pumping head $h_{\text {opt }}$ ) at best efficiency point. Due to the design parameters' nature, the PAT will be characterized by relatively high specific speeds ('high' discharge, 'low' hydraulic head) and the feed pump by lower values ('low' supply discharge, 'high' pumping head).

$$
n_{q, \mathrm{PAT}}=n_{\mathrm{PAT}} \frac{\sqrt{Q_{\mathrm{opt}}}}{\left(H_{\mathrm{opt}}\right)^{0.75}} \quad n_{q, \mathrm{pump}}=n_{\mathrm{pump}} \frac{\sqrt{q_{\mathrm{opt}}}}{\left(h_{\mathrm{opt}}\right)^{0.75}}
$$

Independent from its operation mode (regular or reversed operation), the specific speed of a centrifugal pump corresponds with the constructional design of impeller and housing (see Fig. 9). Therefore, a proper machine type can be selected depending on the respective boundary conditions discharge, head, and operating speed, as long as the following aspects are considered. Constructional constraints apply at specific speeds below approx. $8 \mathrm{~min}^{-1}$ as well as beyond $400 \mathrm{~min}^{-1}$ (Gülich 2010). Deceeding the lower limit, the ratio of the discharge nozzle's width to the impellers diameter is too extreme, limiting the attainable efficiency and ultimately the technical feasibility. In this case, the specific speed can be increased by splitting the pumping head on single impellers of multi-stage pumps (then $h_{\mathrm{opt}}$ is divided by the number of stages). Transcending the upper limit of the specific speed's permitted range the circumferential speed is too high, wherefore the construction's mechanical strength might be exceeded. Then, either the application of double-entry pumps is possible resulting in a calculational reduction of the machine's discharge by $50 \%$ (only one half of the pump's casing is considered), or the setup of various machines in parallel mode can be pursued, whereby single machines can be started and stopped individually depending on the respective discharge (Fig. 8).

In general, the selection of a certain machine type resp. construction form is interconnected with the parameter specific speed, as shown in Fig. 9. Regarding the dependency of specific speed and operating speed (see Eq. 3.5) in association with the mechanical coupling of PAT and feed pump, it is of vital importance that either machines with similar nominal speed have to be selected or a speed transmission through an interposed gearbox is required. To decide about applying a gearbox, it has to be considered that this additional component will lead to a more 


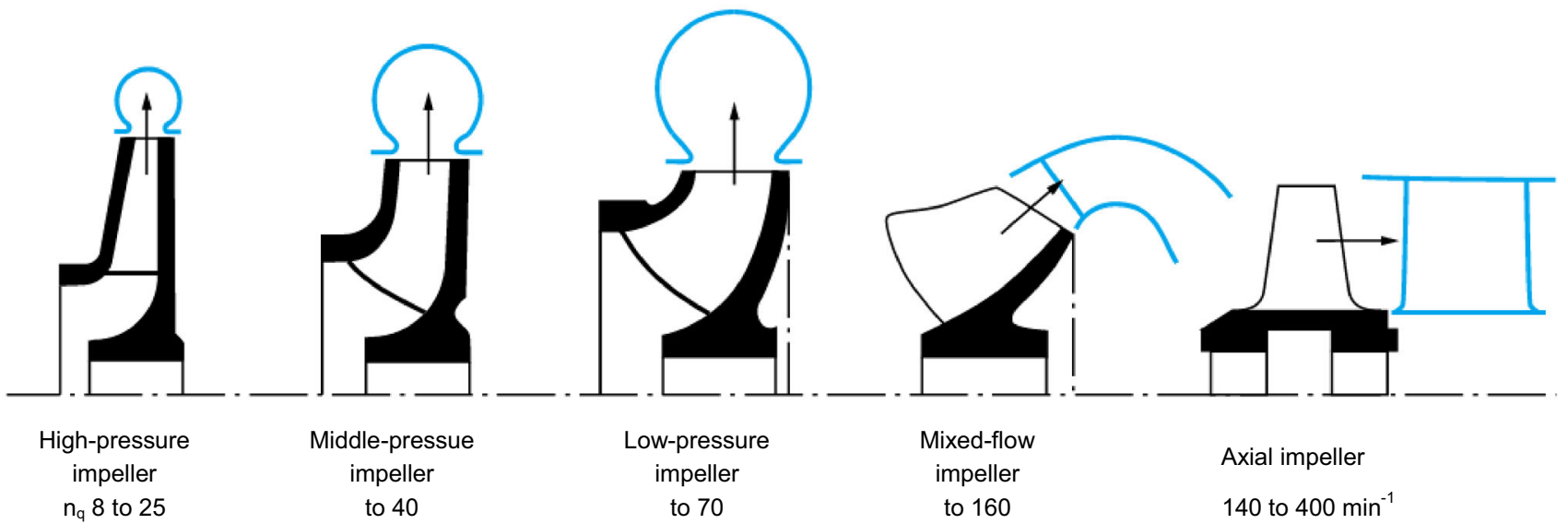

Fig. 9 Interconnection between constructional design of a centrifugal pump's impeller (guide apparatus resp. casing of single-stage pumps are implied) and specific speed, modified from Hellmann (2009)

sophisticated and commonly less robust technical design. Depending on the on-site conditions, however, the application of a gearbox might increase the supply system's overall efficiency despite energetic losses through splashing and friction by enabling the operation of PAT and pump at their respective best efficiency points. Against this background and in consideration of the intended low-cost and low-effort water supply approach, the minimization of the supply system's complexity is desirable. Consequently, setups without gearbox shall be preferred unless technical and/or efficiency related reasons lead to the indispensability of speed transmission.

\section{Design of the demonstration facility}

To achieve the objective of a technology and knowhow transfer regarding the PAT-based water supply concept, it was decided to implement two differently constructed water conveying modules. By applying a gearbox for one of the modules, it can be shown that the boundary conditions of a single site can allow different design approaches, which both enable a sustainable water supply (Fig. 10).

As a consequence, Module 1 is labeled as 'advanced' solution, since the containment of a gearbox leads to a more sophisticated, while more complex application. Here, machines of different production series were applied, which on the one hand increases the O\&M-related technical and financial effort. On the other hand, both measures were chosen with due regard to a high overall efficiency, which considerably influences the attainable total water supply over the operational lifetime. Module 2 comprises a direct coupling of PAT and feed pump without gearbox, whereby both machines originate from the same production series. This setup is designated as 'robust' design, since the O\&M-related expenses were minimized by relinquishing a gearbox as well as by applying only one machine type.

Since the dimensioning of each module was based on the minimum discharge, at least one module is operable at any time. As long as the water yield is sufficient, both
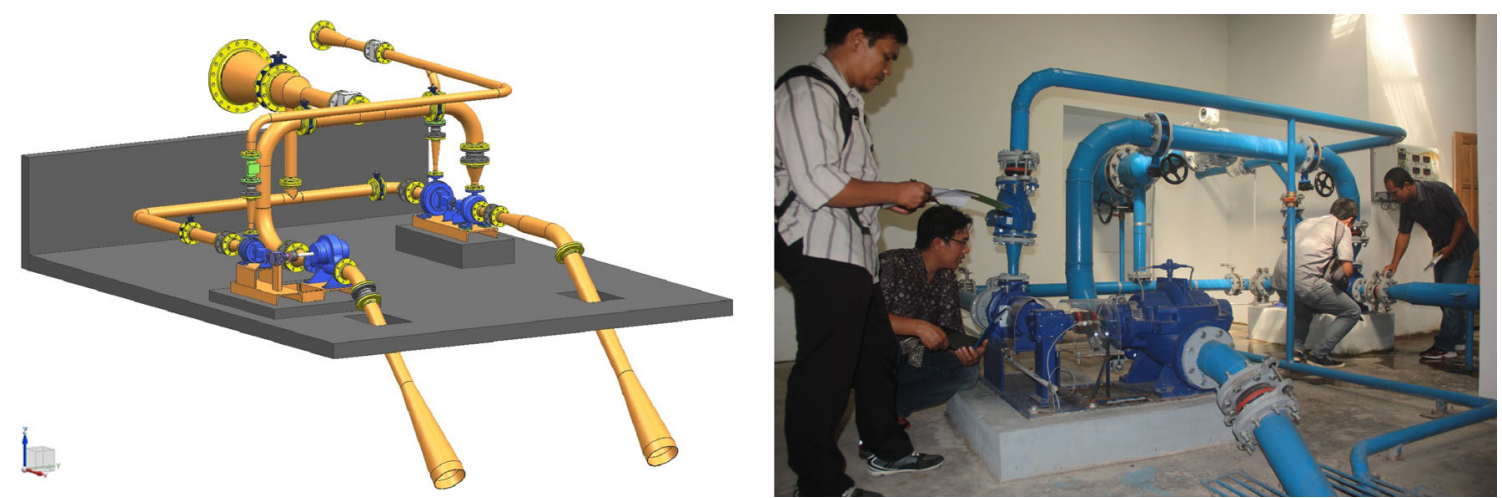

Fig. 10 3D CAD model of the water supply system created in cooperation of KIT, KSB AG, and UGM (left), usage of the supply system during lectures by Indonesian students (right) 
modules can be operated in parallel. Based on these preconditions, the machinery was selected in cooperation of KIT and the German pump manufacturer KSB AG. Within the scope of test-rig runs, different operating conditions were simulated to validate the modules' performances and to obtain the machines' characteristic curves. As expected, the influence of the machines' small construction sizes lead to efficiencies which are lower than the values which can be expected for medium- and large-scale applications.

In general, through variation of hydraulic head and pumping head during operation of the demonstration facility at UGM, the characteristic curves gained on the test field of KSB AG can be reproduced on-site.

\section{Implementation process}

As agreed both by German and Indonesian side during the collaborative development process, the crucial construction works required the accompaniment of technical experts from both sides. This particularly concerned the construction of the wood stave penstock as well as the installation of the timber-concrete-steel connection, the machinery, and the monitoring devices. Accordingly, the respective working steps were accompanied by German staff members of KIT's Institute for Water and River Basin Management (hydraulic engineering), the Institute of Concrete Structures and Building Materials (civil engineering), and of the Research Center for Steel, Timber, and MasonryTimber Structures and Building Constructions (timber engineering), as well as by the respective counterparts from UGM. This collaborative supervision was important to immediately adapt working procedures in the case of need as exemplarily shown with the case of the injection campaign described in Sect. "Connection techniques for wood stave penstocks and steel connectors".

To further support, a sustainable technology and knowhow transfer, comprehensive teaching materials were elaborated by KIT. In addition to a technical handbook, which contains information regarding the operation and maintenance-related tasks, self-explanatory technical posters were designed as shown in Fig. 11 to describe the plant's overall purpose as well as its key features (wooden penstock and PAT-driven supply system). Through the creation of general and specific posters, the content is adapted for target persons with technical and non-technical backgrounds.

To provide data to assess the plant's performance, e.g., carried out by students during practical lectures, a solarpowered monitoring system was developed and implemented. This system measures and displays the operating parameters rotation speed, hydraulic head, pumping head, and supply discharge. As described in Sect. "Benefit as teaching and research facility", these values can be altered to experience the impact of each variation to the plant's performance. The energy supply by solar power was chosen to demonstrate a potential solution for a monitoring system of a water supply facility in island mode. Furthermore, the cover of the system's central switching cabinet was illustrated by a local designer (Fig. 11), and illustrates fictional sceneries which could host a real PAT-driven water supply plant. Thus, the understanding of the plant's main features as well as of its overall purpose is distinctly enhanced.

Regarding the plant's function as teaching laboratory, the facility is used for mandatory practical courses of UGM master students, who have chosen 'Hydropower' as their major subject. Furthermore, it is planned to include the students of bachelor programs and of UGM's vocational school as well. Potential research focuses are, among others, the technical and educational assessment of the applied technologies during operation with respect to further adaptation to the needs and knowhow of local users. In this context, potential construction sites for multiplication purposes can be investigated within field studies (e.g., carried out within the frame of lecturing courses).

\section{Summary}

Implementing a technical facility to sustainably improve the water supply situation in remote areas is a demanding endeavor, especially in emerging and developing countries. A crucial precondition is the availability of a suitable resp. adaptable technical concept as well as of the related knowhow. In this context, the German-Indonesian joint R\&D project "IWRM Indonesia", funded by the German Federal Ministry of Education and Research (BMBF), aimed at the development and introduction of adapted technologies to the water sector of karst areas. Regarding this technology and knowhow transfer process, the focus was set on the exemplary implementation of the innovative solutions.

It has to be considered that due to the uniqueness of each region afflicted with difficult-to-access water resources, an applicable supply concept has to respect local natural and sociological boundary conditions to avoid negative impacts, e.g., on the local ecology. Furthermore, since a single concept might not be transferable to arbitrary locations, two supplementary conceptions regarding a sustainable water supply were developed by KIT. One concept aims for damming up an underground river to provide operating energy for a hydropower-driven water supply system. This conception was successfully implemented in a remote karst area on Java Island, Indonesia, securing the all-season water supply for some 75.000 people. However, due to its remote location, this facility's support of the 

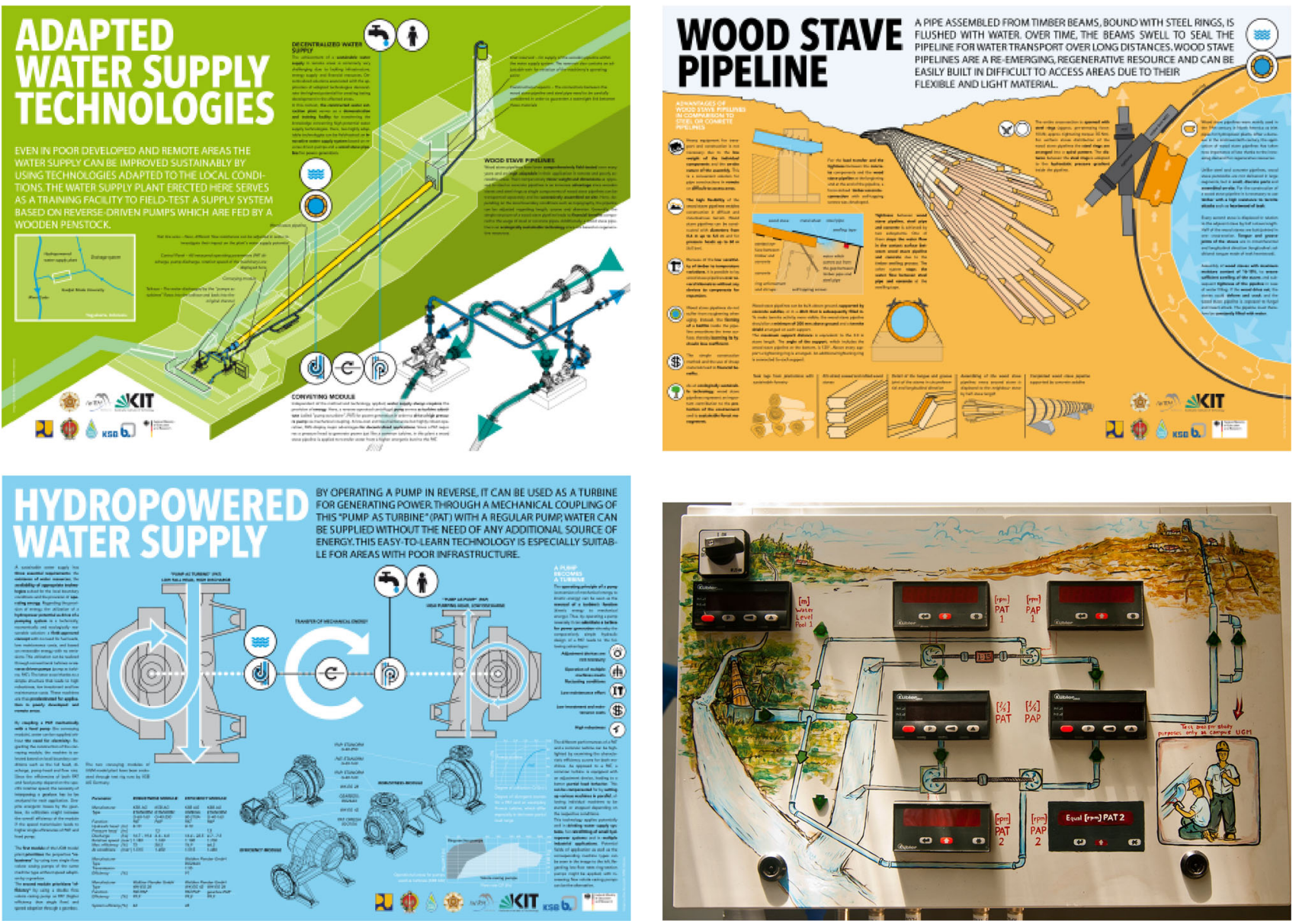

Fig. 11 Posters describing the plant's key features (top, bottom left), design of the monitoring system (bottom right)

knowhow dissemination process is limited. Therefore, the second concept was implemented within the municipal area of Yogyakarta, which hosts among others several internationally accredited universities, non-governmental organizations, regional public authorities, and industries. Here, on the campus of Gadjah Mada University (UGM), a demonstration facility was realized in close cooperation with scientific and industrial partners from both countries.

The here implemented supply concept contains a wood stave penstock to provide a hydraulic head for a hydropower-driven pumping system. As a result of its energetic independence and its high constructive flexibility, this concept is predestinated for decentralized surface and underground applications in various regions afflicted with difficult-to-access water resources.

Against this background, this facility serves three main objectives, namely: (1) as a field lab for teaching of (local) students, (2) as research object ('field laboratory') for (local) scientific staff, as well as (3) as demonstration object for external stakeholders from companies and public authorities. Since vital practical experiences related to this supply concept are gained through working with the demonstration facility, the operators are potential multipliers for the applied technologies.

Acknowledgments The authors would like to thank the German Federal Ministry of Education and Research (BMBF) as well as all related industry partners for continuously supporting the $R \& D$ activities.

Open Access This article is distributed under the terms of the Creative Commons Attribution 4.0 International License (http:// creativecommons.org/licenses/by/4.0/), which permits unrestricted use, distribution, and reproduction in any medium, provided you give appropriate credit to the original author(s) and the source, provide a link to the Creative Commons license, and indicate if changes were made.

\section{References}

Banfi G (2012) Planung einer wasserkraftbetriebenen Wasserförderanlage in Yogyakarta, Indonesien, unter Verwendung einer Holzdruckrohrleitung und "Pumpen als Turbinen"(PAT)-Technologie zur Energiegewinnung. Diploma thesis at KIT 
Blass HJ, Fellmoser P (2005) Druckleitung aus Holz. 3. Karlsruher Berichte zum Ingenieurholzbau. Universitätsverlag Karlsruhe, Germany

Chapallaz JM, Eichenberger P, Fischer G (1992) Manual on pumps used as turbines. Braunschweig, Friedrich Vieweg \& Sohn Verlag

Fellmoser P (2007) Druckrohrleitungen aus Holz-Anwendung und Bemessung. 9. Karlsruher Berichte zum Ingenieurholzbau. Universitätsverlag Karlsruhe, Germany

Ford D, Williams P (2007) Karst hydrology and geomorphology. Wiley, Chichester, p 563

Gülich JF (2010) Kreiselpumpen-Handbuch für Entwicklung, Anlagenplanung und Betrieb, 3rd edn. Springer Verlag Heidelberg, ISBN 978-3-642-05478-5

Hellmann DH (2009) Kreiselpumpen-Lexikon. 4. Überarbeitete und erweiterte Auflage. KSB Aktiengesellschaft (Hrsg.). Ottweiler Druckerei und Verlag GmbH. ISBN 978-3-00-029711-3. December 2009

Khennas S, Barnett A (2000) Best practice for sustainable development of micro hydro power in developing countries. Technical report of the Joint UNDP/World Bank energy Sector Management Assistance Programme (ESMAP)

Madu CN (1989) Transferring technology to developing countriescritical factors for success. Long Range Plan 22(4):115-124

Nestmann F, Oberle P, Ikhwan M, Klingel P (2010) Adaptive water resources management under extreme climatic and hydrological conditions. Interdisciplinary Research Activities in Karst Regions of South East Asia. Proceedings of IWRM Karlsruhe 2010, pp 300-307

Nestmann F, Oberle P, Ikhwan M, Stoffel D (2012) Experiences concerning the implementation of innovative technologies and management strategies in emerging countries: example IWRM Indonesia. Proceedings of the IWRM Karlsruhe 2012, Karlsruhe, November 21-22, 2012, pp 41-53

Oberle P, Ikhwan M, Nestmann F, Fritz J, Ravisundar T (2009) Angepasste Wasserfördertechnologie unter Einsatz von Pumpen im Turbinenbetrieb. WasserWirtschaft 99, Heft 7-8

Oberle P, Ikhwan M, Stoffel D, Nestmann F (2016) Adapted hydropower-driven water supply system: assessment of an underground application in an Indonesian karst area (working title). Submitted to Applied Water Sciences

Putranto K, Stewart D, Moore G (2003) International technology transfer and distribution of technology capabilities: the case of railway development in Indonesia. Technol Soc 25:43-53

Singh P (2005) Optimization of internal hydraulics and of system design for pumps as turbines with field implementation and evaluation. Ph.D. Dissertation, Institute for Water and River Basin Management, Karlsruhe Institute for Technology (KIT)

Störzer G (2009) Einsatz von Pumpen als Turbinen (PAT) im Fallleitungsbetrieb des Zweckverbandes Landeswasserversorgung. In: WasserWirtschaft 99, Heft 7-8

UN Water (2007) Coping with water scarcity: challenge of the twenty-first century. FAO World Water Day

UN Water (2009) Water in a changing world. The United Nations World Water Development Report 3. Unesco Publishing

Yin JZ (1992) Technological capabilities as determinant of the success of technology transfer projects. Technol Forecast Soc Chang 42:17-29 